\title{
Management of the calving pen is a crucial factor for paratuberculosis control in large dairy herds
}

\author{
Karsten Donat, ${ }^{* 1}$ Mandy Schmidt, $†$ Heike Köhler, $\ddagger$ and Carola Sauter-Louis $\S$ \\ ${ }^{*}$ Animal Health Service, Thuringian Animal Diseases Fund, Victor-Goerttler-Straße 4, 07775 Jena, Germany \\ †Animal Health Service, Saxon Animal Diseases Fund, Löwenstraße 7a, 01099 Dresden, Germany \\ łInstitute of Molecular Pathogenesis, Friedrich-Loeffler-Institut, Federal Research Institute for Animal Health, Naumburger Straße 96a, \\ 07743 Jena, Germany \\ §Institute of Epidemiology, Friedrich-Loeffler-Institut, Federal Research Institute for Animal Health, Südufer 10, 17493 Greifswald-Insel Riems, \\ Germany
}

\begin{abstract}
Improvement of hygiene and herd management to reduce the contact of calves with adult cow feces to prevent new infections is one of the basic strategies to manage paratuberculosis-affected dairy herds. Control programs should recommend an evidence-based selection of factors that demonstrably reduce the transmission of the infectious agent and decrease the prevalence of infected cattle to improve acceptance and implementation of the recommended measures among farmers. This study aimed to assess the influence of several management measures on control success in a longitudinal study in 28 large dairy herds with a median size of 415 cows in Thuringia, Germany. The cumulative incidence of cows shedding Mycobacterium avium ssp. paratuberculosis (MAP) per year was determined by individual fecal culture of all cows during 5 consecutive years. Relevant management practices as well as herd size, milk yield, and purchase of cattle were recorded by on-farm risk assessment. Mean holding time of MAP shedders within the herd was calculated from individual data of each shedding cow. Using multiple regression models, separate calving pens for shedders and disinfection of the pen after use were identified as significant risk factors that reduced the cumulative incidence of MAP shedders per year on the herd level. The results provide evidence that, in addition to other factors, calving hygiene and management of the calving pens are crucial for paratuberculosis control, particularly in large dairy herds. Considered together with the outcome from other studies, these results might be important to weight various risk factors and to avoid overburdening and overwhelming farmers and keeping them committed.
\end{abstract}

Received November 11, 2015

Accepted January 17, 2016.

${ }^{1}$ Corresponding author: kdonat@thueringertierseuchenkasse.de
Key words: Mycobacterium avium ssp. paratuberculosis, control measure, management practice, risk factor

\section{INTRODUCTION}

Paratuberculosis, or Johne's disease, is caused by Mycobacterium avium ssp. paratuberculosis (MAP). The majority of new infections probably occur in newborn calves and youngstock, because they are believed to be the most susceptible animals in the herd, and the direct fecal-oral route is generally considered the most important transmission route (Sweeney et al., 2012). In utero infections occur in 20 to $60 \%$ of fetuses from clinically affected cows (Whittington and Windsor, 2009), whereas these infections are seldom observed in calves born to cows shedding low numbers of MAP (Adaska and Whitlock, 2012). In addition, bio-aerosols such as dust from the barn should be considered as transmission routes, as recent experiments have shown that inhalation of MAP can result in infection (Eisenberg et al., 2011). The infection causes a chronic granulomatous enteric disease, predominantly of ruminants, that is characterized by a long incubation period, therapy-resistant aqueous diarrhea, and formation of edema due to hypoproteinemia (Tiwari et al., 2006). Decreased milk production occurs even in cows without clinical symptoms (Raizman et al., 2007a; Smith et al., 2009; Donat et al., 2014a). Premature culling (Smith et al., 2010) and increased susceptibility to other diseases (Raizman et al., 2007b) reduce the farmer's income (Wolf et al., 2014). Furthermore, a link between Crohn's disease, a human inflammatory bowel disease, and MAP has been noted and therefore a role of MAP as a potential zoonotic pathogen is suspected (Over et al., 2011; Sweeney et al., 2012). Considering the economic impact of paratuberculosis and the potential risk for human health, control measures should be implemented in MAP-positive herds.

Effective paratuberculosis control programs involve 3 main objectives: first, to prevent new infections by bios- 
ecurity and hygiene management; second, to reduce the number of infected animals that may shed MAP (test and cull strategies); and third, to improve resistance to paratuberculosis through vaccination or genetic selection (Sweeney et al., 2012). Purchase and introduction of animals are important risk factors associated with the introduction of the infectious agent into the herd (Künzler et al., 2014; Rangel et al., 2015). Usually, improving management practices and the standard of hygiene to reduce calf exposure to infected manure is highly recommended in many control programs, as it is cost-effective in reducing MAP transmission as well as other diseases transmitted by the fecal-oral route in most operations (McKenna et al., 2006).

In MAP-positive herds, calves are presumably exposed to feces from cattle that shed the infectious agent. Ingestion of the bacteria from the environment is important because MAP can persist in the environment at $5^{\circ} \mathrm{C}$ for more than $9 \mathrm{mo}$, at $15^{\circ} \mathrm{C}$ for at least $3.5 \mathrm{mo}$, and in a dry, fully shaded environment for up to $55 \mathrm{wk}$ (Lovel et al., 1944; Jørgensen, 1977; Whittington et al., 2004). In manure stored in lagoons, viable MAP was found after 8 wk and MAP DNA after $175 \mathrm{~d}$ (Grewal et al., 2006). Transmission of the agent is believed to be stopped most effectively by preventing newborn calves and youngstock from contact with any matter that may contain feces from adult cattle, be it milk or colostrum, water, feed, dust, or other sources (Doré et al., 2012). Although studies have shown evidence for an age-dependent susceptibility, with a high risk of infection when exposure to the infectious agent occurs at birth (Windsor and Whittington, 2010), calves up to 12 mo of age are susceptible to infection (Mortier et al., 2013). This is particularly important if the dam is infected or the environment is highly contaminated. Because of the many possible ways in which calves can become exposed to MAP, numerous recommendations for decreasing the risk of new infections in dairy herds have been published and summarized (McKenna et al., 2006; Sweeney et al., 2012) and adopted as guidelines. Trying to cover the majority of infection routes, these guidelines have become complex and may overwhelm and overburden farmers. Furthermore, producers consider most of the recommended measures expensive and difficult to implement and maintain (Campe et al., 2014). Due to the long interval between exposure to the infectious agent and detectable disease and because of the various transmission routes, it is difficult to quantify the significance of recommendations related to minimizing calf exposure to the infectious agent, and there appears to be a lack of published knowledge concerning this question (McKenna et al., 2006). Doré et al. (2012) reviewed 23 studies, published between
1950 and 2010, concerning risk factors associated with MAP transmission to dairy calves. Most of the studies were cross-sectional and based on ELISA testing. Five of these studies referred to a case definition based on detection of the organism, and only one of those, which was conducted in a Dutch dairy herd, had a longitudinal design and referred to new cases or incidence. The contact of calves with adult cow feces was found to be the most important risk factor.

In addition, studies published between 2010 and 2014 have been reviewed. Pillars et al. (2011) found the exposure to adult cows other than the dam at birth and feeding colostrum from one cow to multiple calves to be significant risk factors. Furthermore, in 226 Canadian dairy herds grouped on milk ELISA results, the purchase of cattle during the last $20 \mathrm{yr}$ and the number of calves with diarrhea were significant risk factors for a herd to be MAP positive, and monensin feeding to cows and high frequency of feeding of pooled colostrum were associated with increasing numbers of cows being positive by milk ELISA (Sorge et al., 2012). In a longitudinal study in 21 Canadian dairy herds on the effect of changing management practices, no hygiene-related factors were identified that influenced the incidence rate of MAP shedders (Arango Sabogal et al., 2014). A cross-sectional study in Brazil identified not using a maternity pen as a risk factor (Vilar et al., 2015), and a Swiss case-control study found several factors related to contamination of the youngstock area with manure from adults and the management of the calving area to be associated with within-herd prevalence (Künzler et al., 2014). A study in 3 Minnesota dairy herds provided evidence that calves born in an individual calving pen had a lower hazard ratio for testing MAP positive in subsequent years compared with cows born in group calving pens (Pithua et al., 2013).

Therefore, the objective of this study was to assess the influence of management practices and hygiene measures on the incidence of cows shedding MAP in a longitudinal study of herds participating in the Thuringian control program. We hypothesized a significant influence of several management practices on the reduction of MAP shedder's incidence within a 5-yr control period.

\section{MATERIALS AND METHODS}

\section{Study Herds and Cumulative Incidence}

Since 2003, voluntary paratuberculosis control programs have been offered to dairy farmers in the German federal states of Thuringia and Saxony. Both programs include, among other measures, annual screening of 
all cows for MAP by fecal culture (FC) on Herrold's egg yolk medium as described previously (Donat et al., 2014b). Cows that are MAP positive are scheduled to be culled as outlined by Sweeney et al. (2012), who recommend immediate culling of heavy shedders and an elimination of low shedders at the end of the lactation or in case of other health problems. The MAPpositive cows that were kept within the herd were not retested in the following year. This procedure implied that only new cows (first lactation or purchased cows) and previously negative cows were scheduled for testing. Cumulative incidence (CumInc) was calculated from the new FC MAP-positive cows over the mean number of cows kept within the herd in each year.

Twenty-eight Holstein MAP-positive dairy herds enrolled in the paratuberculosis control programs in Thuringian and Saxon cattle herds between 2008 and 2012 were selected for this study. All herds were housed in freestalls. Descriptive statistics of the herd size and the CumInc of cows shedding MAP within each herd are given in Table 1. Because the number of cows kept within each herd varied slightly during the study period, the average number of cows kept during the years 2008 to 2012 was calculated and reported as herd size.

\section{On-Farm Management and Hygiene Assessment}

From 2003 through 2007, animal health service veterinarians advised the owners of the herds enrolled in the control program to improve farm and hygiene management. To evaluate the implementation of these recommendations, a questionnaire-based risk assessment tool was developed by the veterinarians of the Thuringian Animal Health Service (Jena, Germany). The questionnaire covered 32 on-farm management practices (Supplementary Table S1; http://dx.doi.org/ jds.2015-10625) that were related to current knowledge concerning management recommendations to improve hygiene management in the context of paratuberculosis control strategies (Sweeney et al., 2012). In short, the questionnaire included the following aspects:

- calving hygiene (questions 1-12): location of the calving pen within the barn; separate calving pen for MAP shedders; average number of cows in a calving pen; kind of litter; separation, cleaning, and disinfection of the calving pen; disinfection of calving pens for known MAP shedders after use; average time span between calving and separation of newborn calves from their dam; cleanliness/ cleaning of cows before introduction into the calving pen; cleaning of neonates after calving; cleaning and disinfection of obstetric instruments;

- colostrum management (questions 13-20): cleanliness of milking colostrum; source of colostrum used for first feeding and traceability/documentation; average time span between calving and first feeding of colostrum; storage of colostrum for first feeding; cleanliness of drinking vessels; use of milk from known MAP shedders to feed calves;

- calf and youngstock rearing (questions 21-32): location of pens for calves and youngstock within the barn; cleaning and disinfection of calf pens; personal hygiene of calf keepers; cleanliness of feeding barns; feeding of mixed colostrum/tank milk to calves; quality of roughage (hay, haylage, silage) for calves in the first 2 mo; cleanliness of tools, equipment, and machines used in handling calves; cleaning and disinfection of calf pens after occupancy; pasturing of calves together with cows.

Furthermore, herd size, milk yield (average 305-d milk production, $\mathrm{kg}$ ), and purchase of cattle (own restocking, sporadic or general purchase) were recorded. The response categories for all questions had scores from 1 to 3, increasing with assumed increased risk of

Table 1. Herd size, cumulative incidence of cows with fecal shedding of Mycobacterium avium ssp. paratuberculosis (MAP) within the years 2008 to 2012, and holding days of MAP shedders

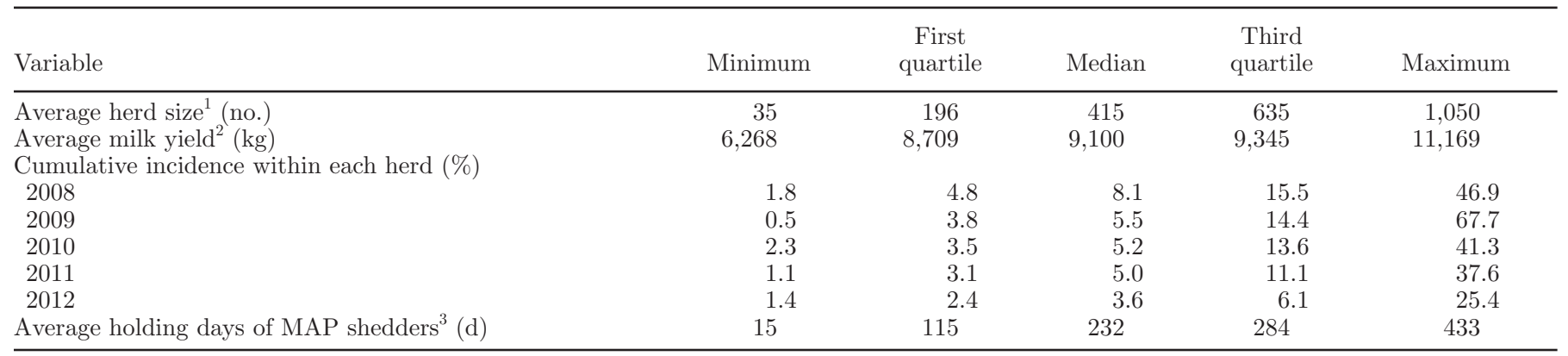

${ }^{1}$ Average number of cows kept within the herd between 2008 and 2012.

${ }^{2}$ Average $305-\mathrm{d}$ milk production in the year of the risk assessment (i.e., period of the DHI test).

${ }^{3}$ Average holding days of MAP shedders within the herd after reporting the test result. 
spreading MAP within the herd. Response category 2 represented the common situation in herds participating in the control program as perceived by the animal health service veterinarian (standard). For each trait, the management practices presumed to minimize the spread of MAP better than the standard were categorized as 1 (better), and those that may have increased the risk of MAP spreading as 3 (worse). Therefore, we presumed that the response category scores were a fair representation of a reduced or enhanced risk of spreading MAP through this management practice.

The risk assessment was conducted in 2010 or 2011 by 6 animal health service veterinarians in 55 control program herds in Thuringia and Saxony; from those, the 28 study herds were selected as described above. During these on-farm visits, owners of the study herds were advised not to change their management practices during the study period. They were told they would obtain further information on how to improve management once the analysis of the study was finished. As they had previously improved their management considering paratuberculosis control to an extent they could afford and manage permanently, they were content with this agreement and, in general, management practices were not modified during the study.

For each MAP-positive cow, the time span between the date when the test result was reported to the owner and the date of culling or slaughtering was calculated. The date of reporting the test result was retrieved from the laboratory databases of the laboratories involved (laboratory of the Thuringian Animal Health Service, Jena, Germany; Saxon state laboratory, Dresden, Germany). The date of culling or slaughtering was extracted from the German database of animal origin (HI-Tier, administered by the Bavarian Ministry of Food, Agriculture and Forestry, Munich, Germany). The arithmetic mean of holding days calculated from all MAP-positive cows was calculated for each herd. We used this herd-level variable as an estimate for compliance of the owner to cull MAP-positive cows.

\section{Risk Factor Analysis}

All computations were made using SPSS for Windows (version 19; IBM, Armonk, NY), and the significance level was set at $\alpha=0.05$. As a correlate of control measures success, the shifting of the CumInc from 2008 to 2012 was used. To account for the different initial levels of CumInc in a particular herd, the relative shifting of CumInc $\left(\boldsymbol{\Delta} \mathbf{C u m I n c}_{\text {rel }}\right)$ was calculated as follows:

$$
\begin{gathered}
\Delta \text { CumInc }_{\text {rel }}(\%)= \\
{\left[\operatorname{CumInc}_{2012}(\%)-\text { CumInc }_{2008}(\%)\right] / \operatorname{CumInc}_{2008}(\%),}
\end{gathered}
$$

where $\Delta$ CumInc $_{\text {rel }}=$ relative shifting of CumInc during the study; $\mathrm{CumInc}_{2008}=$ CumInc in 2008; and CumInc $_{2012}=$ CumInc in 2012.

To identify risk factors associated with $\Delta$ CumInc $_{\text {rel }}$, a multiple linear regression model was used. All variables were tested in a univariable analysis against $\Delta$ CumInc $_{\text {rel }}$ using the Kruskal-Wallis test procedure, where 3 classes were used according to the response categories of the risk factor analyses. In case of low frequencies $(\leq 5)$ in one class, classes were merged with one of the other classes according to meaningful practical aspects and analyzed using the Mann-Whitney U-test. Because of the large number of variables and the limited effective sample size, only those variables that had a $P$-value $\leq 0.1$ in the univariable analysis were included in the model. One herd with an extreme relative shifting of CumInc was identified as an outlier and excluded from the regression analysis. Through stepwise regression with backward elimination, only predictors with $P \leq$ 0.05 remained in the final linear model.

The formula of the linear regression model used was

$$
\begin{gathered}
\Delta \text { CumInc }_{\text {rel }}=\mathrm{a}+\mathrm{b}_{1}\left(\mathrm{CP} \_ \text {sep }\right)+\mathrm{b}_{2}\left(\mathrm{CP} \_ \text {dis }\right) \\
\left.+\mathrm{b}_{3}(\text { col_source })+\mathrm{b}_{4} \text { (pers_hyg }\right),
\end{gathered}
$$

where $\Delta$ CumInc $_{\text {rel }}=$ relative shifting of cumulative incidence during the study; $C P \_s e p=$ separate calving pen for MAP-positive cows; CP_dis $=$ disinfection of MAP shedder's separate calving pens; col_source = source of colostrum for first feeding; pers_hyg = staff hygiene in calf and youngstock holdings; $\mathrm{a}=$ constant; and $\mathrm{b}_{1}, \ldots$,

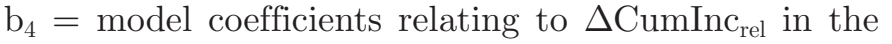
regression model.

Parameters were tested for multicollinearity. Only the correlation between the parameter "disinfection of MAP shedder's separate calving pen" and the parameter "staff hygiene routine when entering calf area" showed correlation $(\mathrm{r}=0.539)$, thus the model was calculated once omitting the parameter "disinfection of MAP shedder's separate calving pen" and a second time omitting the parameter "staff hygiene routine when entering calf area." Pairwise interactions were investigated. The fit of the model was assessed using the adjusted coefficient of determination and Schwarz's Bayesian information criterion (BIC).

For further analysis, herds were classified as "effective" if $\Delta$ CumInc $_{\text {rel }}$ was less than or equal to $-50 \%$ and "not effective" if $\Delta$ CumInc rel was greater than $-50 \%$. Concerning management practices as influencing factors of interest, their relation to the dichotomized $\Delta$ CumInc $_{\text {rel }}$ category (effective or not effective) was assessed using a logistic regression model. Contingency tables and the Mann-Whitney U-test procedure were 
used for univariable analysis. Classes of low frequencies were combined with other classes on biological reasoning. Variables with $P \leq 0.1$ were included into the multivariable logistic model. By starting a stepwise regression with backward elimination, only those predictors with $P \leq 0.05$ remained in the final model.

The formula of the logistic model used was

$$
\begin{aligned}
\operatorname{logit}\left(\mathrm{P}_{\text {eff }}\right)= & \mathrm{a} \\
+ & \mathrm{b}_{1}\left(\mathrm{CP} \_ \text {sep }\right)+\mathrm{b}_{2}\left(\mathrm{CP} \_ \text {dis }\right) \\
& +\mathrm{b}_{3}(\text { pers_hyg }),
\end{aligned}
$$

where $\mathrm{P}_{\text {eff }}=$ probability of effective control $\left(\Delta\right.$ CumInc $_{\text {rel }}$ $\leq-50 \%)$; CP_sep $=$ separate calving pen for MAPpositive cows; $\mathrm{CP} \_$dis $=$disinfection of MAP shedder's separate calving pen; pers_hyg = staff hygiene in calf and youngstock holdings; $\mathrm{a}=$ constant; and $\mathrm{b}_{1}, \ldots, \mathrm{b}_{3}$ $=$ model coefficients relating to $\mathrm{P}_{\text {eff }}$ in the logistic regression. The model fit was assessed using Nagelkerke's pseudo R-square.

\section{RESULTS}

\section{Cumulative Incidence}

The average CumInc of MAP shedders in the 28 study herds decreased within the period of the study from $8.1 \%$ in 2008 to $3.6 \%$ in 2012 . There was a wide range from 1.8 to $46.9 \%$ at beginning of the study. During the study period, CumInc exceeded $30.0 \%$ in only 2 herds. The distribution of the CumInc per herd and year is given in Table 1. For 13 herds that were classified as effective regarding the effect of the control measures, a relative shift of CumInc of less than or equal to $-50 \%$ was achieved, whereas 15 herds did not reach that level of reduction and were classified as not effective.

\section{Univariable Analysis}

In the univariable analysis, 4 variables were identified with a $P$-value $<0.1$ ("separate calving pen for MAPpositive cows," "disinfection of MAP shedder's separate calving pen," "source of colostrum for first feeding," and "staff hygiene in calf and youngstock holdings"). These 4 variables were selected for the multiple regression models. Regarding the variables "use of colostrum from MAP-positive cows for calf feeding" and "nonsaleable milk fed to calves," most of the herds had implemented the recommendations concerning hygiene improvement, as 24 herds discarded colostrum of MAP shedders and 4 herds used it after pasteurization but not for first feeding. Nonsaleable milk was not fed to calves kept for restocking in 21 herds, used after pasteurization in 6 herds, and fed without pasteurization in only 1 herd. The average number of cows in a calving pen exceeded 3 cows in 13 herds. Only 4 herds managed separate calvings for each cow (Supplementary Table S1; http:// dx.doi.org/jds.2015-10625).

Regarding the herds with a relative shift of the CumInc of less than $-50 \%$ (i.e., effective control), 6 herds had separate staff in calf and youngstock holdings compared with 2 in the "not effective" control farms. In contrast, 5 of the latter did not implement any measures to ensure good personal hygiene of calf and youngstock keepers (Supplementary Table S1).

\section{Multiple Linear Regression}

Four variables with a $P$-value $<0.1$ were included in the multiple regression model. Using stepwise regression with backward elimination including all 4 variables or using 3 variables and omitting 1 of the correlated variables resulted in the same final model, with only one predictor variable remaining - the separate calving pen for MAP-positive cows (Table 2). Although this single variable explained $16.8 \%$ of the variation, the outcome indicates that this variable is a significant predictor of lowering the CumInc.

\section{Multiple Logistic Regression}

To distinguish herds where control measures effectively reduced the CumInc from those where control measures were not as effective, we used a logistic regression

Table 2. Final multiple linear regression model for risk factors associated with the relative shifting of cumulative incidence of cows with fecal

\begin{tabular}{|c|c|c|c|c|c|c|c|c|c|}
\hline Variable & Coefficient & $\mathrm{SE}$ & \multicolumn{2}{|c|}{$95 \%$ CI } & $\begin{array}{l}\text { Standardized } \\
\text { coefficient }\end{array}$ & $P$ & $\mathrm{R}$ & $\underset{\mathrm{R}^{2}}{\text { Adjusted }}$ & $\begin{array}{c}\mathrm{SE} \mathrm{R}^{2} \\
(\%)\end{array}$ \\
\hline $\begin{array}{l}\text { Separate calving pen for MAP } \\
\text { shedders }\end{array}$ & 56.2 & 22.1 & 10.8 & 101.8 & 0.45 & 0.017 & 0.446 & 0.168 & 50.7 \\
\hline
\end{tabular}
shedding of Mycobacterium avium ssp. paratuberculosis (MAP) in 28 study herds during 5 consecutive years ${ }^{1}$

${ }^{1} 95 \%$ CI $=95 \%$ confidence interval for the nonstandardized coefficient; $P=P$-value of the standardized coefficient; $\mathrm{R}=$ multiple regression coefficient. 
Table 3. Final logistic regression model for risk factors associated with the category ("effective" or "not effective") of the relative shifting of the cumulative incidence of cows with fecal shedding of Mycobacterium avium ssp. paratuberculosis (MAP) in 28 study herds during 5 consecutive years $^{1}$

\begin{tabular}{|c|c|c|c|c|c|c|c|c|}
\hline \multirow{2}{*}{$\begin{array}{l}\text { Variable } \\
\text { Disinfection of separate calving pen } \\
\text { for MAP shedders after use } \\
\text { Constant }\end{array}$} & \multirow{2}{*}{$\begin{array}{r}\beta \\
-1.838 \\
0.452\end{array}$} & \multirow{2}{*}{$\frac{\mathrm{SE}(\beta)}{0.927}$} & \multirow{2}{*}{$\frac{\text { Wald }}{3.935}$} & \multirow{2}{*}{$\frac{P}{0.047}$} & \multirow{2}{*}{$\frac{\operatorname{Exp}(\beta)}{0.159}$} & \multicolumn{2}{|c|}{$\begin{array}{c}95 \% \text { CI } \\
{[\operatorname{Exp}(\beta)]}\end{array}$} & \multirow{2}{*}{$\begin{array}{c}\mathrm{R}^{2} \\
\text { Nagelkerke } \\
0.203\end{array}$} \\
\hline & & & & & & 0.026 & 0.978 & \\
\hline
\end{tabular}

model. The only predictor that was significant in the final model was the disinfection of the separate calving pen for MAP shedders after use. Using Nagelkerke's pseudo R-square, the percentage of variance explained by the model was estimated to be approximately $20 \%$ (Table 3). A separate calving pen for MAP shedders was found in each of the 13 herds with a relative shift of the CumInc of less than $-50 \%$, but in only 6 of the 12 "not effective" control farms. However, this variable was not significant in the logistic regression model.

\section{DISCUSSION}

This study established 2 predictors of successful paratuberculosis control in dairy herds: the installation of a separate calving pen for MAP shedders and its effective disinfection. These findings complement the set of recommendations to manage MAP-positive dairy herds as outlined by Sweeney et al. (2012) and provide additional evidence that MAP infection is associated with the immediate neonatal environment, as reviewed by Doré et al. (2012). Our results emphasize management practices that are particularly important in medium-sized to large dairy farms, which are represented by the herds included in this study. To a much greater extent than small dairy farms, larger operations have the opportunity to create and use such a facility. If the average number of calvings per day is $>1$, a dairy farm needs more than one calving pen to enable regular cleaning of this area and professional disinfection using disinfectants suitable for inactivation of MAP, such as cresols, organic acids, and peroxides. Improving the calving pen's hygiene affects animal health in general and helps specifically in limiting transmission of MAP to newborn calves. The lack of personnel in dairy farms, driven by the high economic pressure of low-priced milk and the scarcity of skilled workers in dairy farming, make it difficult to guarantee a good level of hygiene for each calving throughout the year. Therefore, particular care should be taken when a special risk for MAP transmission is expected: the calving of a MAP shedder. The Danish paratuberculosis control program recommends that "red cows" ( 2 positive milk ELISA results) should be slaughtered before next calving so that they do not enter the calving area (Nielsen and Toft, 2011). In Germany, slaughter of pregnant cows is no longer appropriate for animal welfare reasons. Even Danish farmers state that more than $85 \%$ of the farmers will allow calving of some or most "red cows." In this situation, special emphasis should be given to calving of MAP shedders. A highly practical approach to implement this is to mark shedders and to let them calve in a separate place that will be professionally cleaned and disinfected afterward.

Our findings are in line with the results of a crosssectional study in Brazil, which identified not using a maternity pen as a risk factor (Vilar et al., 2015), and a Swiss case-control study, where the absence of a calving pen in freestalls were associated with higher prevalence of Johne's disease than separate boxes with deep straw bedding and calving in a tethered stable (Künzler et al., 2014).

Furthermore, it is generally agreed that preventing contact between calves and cow feces is a crucial factor to reduce the risk of MAP transmission (Doré et al., 2012). This is supported by the recent findings that herds with higher manure contamination of animals, pens, and feeders have an increased risk (1.31 times) of having at least one positive environmental sample (Adaska and Whitlock, 2012; Sweeney et al., 2012). Furthermore, exposure at birth to adult cows other than the dam is a risk factor for these calves, once they are cows later on, for testing positive for MAP (Pillars et al., 2011). Therefore, MAP shedders should be removed from the herd as soon as possible after detection. Although the mean holding time of MAP shedders after their identification was not a significant variable in our study (Supplementary Table S1; http:// dx.doi.org/jds.2015-10625), the immediate culling of MAP shedders is an effective measure to control the spread of MAP within herds (Kudahl et al., 2011).

Generally, identifying the most important recommendations to improve hygiene management and reduce 
the transmission of MAP within a herd is an important issue and a challenge. The importance results from the fact that usually a long and unranked list of knowledgebased measures is recommended that may overwhelm and overburden farmers. Therefore, numerous studies have shown that distinct factors are risk factors for paratuberculosis transmission. Despite the differences in internal and external validity regarding study design, numbers of involved animals and herds, herd selection, case definition, diagnostic tests, and potential biases, most studies have identified none, one, or a few risk factors. A systematic review (Doré et al., 2012) showed that most of the risk factors were closely related to fecal contamination and hygiene, whereas source of colostrum (for first feeding) or milk (waste or tank milk) appeared to be of less relevance. Moreover, these variables were not found as risk factors in later studies (Pillars et al., 2011; Sorge et al., 2012; Wolf, 2014) nor in our study. However, these practices are biologically plausible and should not be neglected in paratuberculosis control. Neither should hygiene of calf rearing be neglected, as a recent study provided evidence that infected calves can excrete the infectious agent (Wolf et al., 2015).

Therefore, the value of our study is to provide evidence for the significance of the separate calving pen and its disinfection for the successful control of paratuberculosis, but not to exclude other factors as risk factors. For example, nonsaleable milk was not fed to calves kept for restocking in 21 out of 28 herds in our study; hence, the variability of this factor was not sufficient to find significant associations. Although the number of included herds in our study is a limitation, to the best of the our knowledge, it is the first study to use the shift of CumInc of MAP shedders within a time span of 5 consecutive years as a dependent variable. The strength of this study is its design as a retrospective cohort study, the diagnostic test used, and the period covered. Applying FC as diagnostic test to each individual cow each year allows calculation of the CumInc without any selection bias or bias caused by pooling, resulting in a precise identification of new shedders in the respective herd. Another retrospective cohort study, with the herd as the study unit, used data from 137 Australian herds, focused on ELISA-positive and clinical cases, and identified calving in paddocks and feeding of "antibiotic milk" as risk factors (Ridge et al., 2010). The results of that study and our own results demonstrate that, regardless of the diagnostic test used, cohort studies are appropriate to identify risk factors for MAP transmission within a herd. Furthermore, the outcome of any risk factor analysis is influenced by the categorization of the recorded variables. In our study, the original data indicated that the location of calf pens within the barn and the cleanliness of tools and equipment used in areas for calves and youngstock may be important in reducing CumInc. Both variables were deemed significant when using all 3 categories of the risk assessment questionnaire (Supplemental Table S1; http://dx.doi.org/10.3168/jds.2015-10625). Two herds kept calves together with cows, and in 3 herds, tools and equipment used in the calf area were soiled with manure from cows. After merging these categories with other categories of those variables, significance disappeared and the variables were omitted from further analysis. Nonetheless, although the management situation in dairy herds is complex, highly variable, and differs in relation to herd size and business conditions, evidence for a specific number of risk factors could be established.

The management factors "source of colostrum for first feeding," "cleanliness of tools and equipment used in youngstock area," and "staff hygiene routine when entering calf area" are indicators for the implementation of control measures in involved herds. In our study, diversity between herds concerning these traits was only marginal and, therefore, the association was no longer significant when classes were merged or the original data slightly missed the level of significance. Nonetheless, attention should be paid to these factors when on-farm risk assessments are done in practice and farmers are advised regarding the control of paratuberculosis. For example, the cleanliness of tools and equipment used in the calf area and the personal hygiene of calf and youngstock keepers are good indicators of the general hygiene level on a farm, and the significance of these variables lead to the hypothesis that the general hygiene level of farm management may be a good predictor for reduction in MAP incidence. Second, the source of colostrum for first feeding, a factor that slightly missed the significance level in our study $(P=$ 0.075 ), is a biologically plausible risk factor, as previously reported (Diéguez et al., 2008) and is considered one of high importance (Sweeney et al., 2012).

The results of this study lead us to conclude that, at least in medium-sized to large, well-managed dairy herds, a separate calving pen for MAP shedders and its professional hygiene management influence the success of paratuberculosis control. Other management practices such as colostrum management, general hygiene (tools and personnel), and immediate culling of shedders are identified as good candidates for measures of high importance. More research, mainly in longitudinal studies, is needed to determine the impact of distinct management factors on the effectiveness of paratuberculosis control in cattle. 


\section{ACKNOWLEDGMENTS}

This study was part of the "Paratuberculosis control program in Thuringian dairy herds" of the Thuringian Ministry of Social Welfare, Family and Health (Erfurt, Germany), which is financed by the Thuringian Animal Diseases Fund (Jena, Germany). The work was complemented by data from dairy farms in Saxony that were supplied by the Saxon Animal Diseases Fund (Dresden, Germany) and the Saxon State Laboratory (Dresden, Germany). The authors thank these organizations for their support. The authors also thank the veterinarians of the Animal Health Services of the Saxon Animal Diseases Fund (Dresden, Germany), Karin Eulenberger and Rene Pützschel, as well as those of the Thuringian Animal Diseases Fund (Jena, Germany), Andreas Ahrens, Katja Hruschka, Wolfram Siebert, and Stefanie Söllner-Donat, who did the on-farm risk assessment together with the authors.

\section{REFERENCES}

Adaska, J. M., and R. H. Whitlock. 2012. Low rate of detectable in utero transmission of Mycobacterium avium subspecies paratuberculosis in a dairy herd with a low prevalence of Johne's disease. J. Vet. Diagn. Invest. 24:153-155.

Arango Sabogal, J. C., O. Labrecque, J. Paré, G. Côté, J. Roy, S. Buczinski, V. Wellemans, and G. Fecteau. 2014. Impact of changing management practices on the incidence of fecal excretion $[\mathrm{FE}]$ of Mycobacterium avium subspecies paratuberculosis [MAP] in dairy herds enrolled in the Québec voluntary prevention and control program (QVPCP). Page 104 in Proc. 12th Int. Colloq. Paratuberculosis. International Association for Paratuberculosis, Providence, RI.

Campe, A., H. Köhler, and K. Donat. 2014. Approaches to controlling paratuberculosis in Germany-conditioned by voluntariness and federalism. Pages 31-40 in Proc. 4th Paratuberculosis Forum. European Food Safety Authority, Parma, Italy.

Diéguez, F. J., I. Arnaiz, M. L. Sanjuán, M. J. Vilar, and E. Yus. 2008. Management practices associated with Mycobacterium avium subspecies paratuberculosis infection and the effects of the infection on dairy herds. Vet. Rec. 162:614-617.

Donat, K., K. Schlotter, G. Erhardt, and H. R. Brandt. 2014b. Prevalence of paratuberculosis in cattle and control measures within the herd influence the performance of ELISA tests. Vet. Rec. 174:119.

Donat, K., A. Soschinka, G. Erhardt, and H. R. Brandt. 2014a. Paratuberculosis: Decrease in milk production of German Holstein dairy cows shedding Mycobacterium avium ssp. paratuberculosis depends on within-herd prevalence. Animal 8:852-858.

Doré, E., J. Paré, G. Côté, S. Buczinski, O. Labrecque, J. P. Roy, and G. Fectau. 2012. Risk factors associated with transmission of Mycobacterium avium ssp. paratuberculosis to calves within dairy herd: A systematic review. J. Vet. Intern. Med. 26:32-45.

Eisenberg, S. W., A. P. Koets, M. Nielen, D. Heederik, R. Mortier, J. De Buck, and K. Orsel. 2011. Intestinal infection following aerosol challenge of calves with Mycobacterium avium subspecies paratuberculosis. Vet. Res. 42:117.

Grewal, S. K., R. Rajeev, R. Sreekumari, S. Sreevatsan, and F. C. Michele. 2006. Persistence of Mycobacterium avium ssp. paratuberculosis and other zoonotic pathogens during simulated composting, manure packing and liquid storage of dairy manure. Appl. Environ. Microbiol. 72:565-574.

Jørgensen, J. B. 1977. Survival of Mycobacterium paratuberculosis in slurry. Nord. Vet. Med. 29:267-270.
Kudahl, A. B., S. S. Nielsen, and S. Ostergaard. 2011. Strategies for time of culling in control of paratuberculosis in dairy herds. J. Dairy Sci. 94:3824-3834.

Künzler, R., P. Torgerson, S. Keller, M. Wittenbrink, R. Stephan, G. Knubben-Schweizer, B. Berchtold, and M. Meylan. 2014. Observed management practices in relation to the risk of infection with paratuberculosis and to the spread of Mycobacterium avium ssp. paratuberculosis in Swiss dairy and beef herds. BMC Vet. Res. 10:132.

Lovel, R., M. Levi, and J. Francis. 1944. Studies on the survival of Johne's bacilli. J. Comp. Pathol. 54:120-129.

McKenna, S. L., G. P. Keffe, A. Tiwari, J. VanLeeuwen, and H. W. Barkema. 2006. Johne's disease in Canada part II: disease impact, risk factors, and control programs for dairy producers. Can. Vet. J. 47:1089-1099.

Mortier, R. A., H. W. Barkema, J. M. Bystrom, O. Illanes, K. Orsel, R. Wolf, G. Atkins, and J. De Buck. 2013. Evaluation of agedependent susceptibility in calves infected with two doses of $\mathrm{Myco}$ bacterium avium subspecies paratuberculosis using pathology and tissue culture. Vet. Res. 44:94.

Nielsen, S. S., and N. Toft. 2011. Effect of management practices on paratuberculosis prevalence in Danish dairy herds. J. Dairy Sci. 94:1849-1857.

Over, K., P. G. Crandall, C. A. O'Bryan, and S. C. Ricke. 2011. Current perspectives on Mycobacterium avium ssp. paratuberculosis, Johne's disease, and Crohn's disease: A review. Crit. Rev. Microbiol. 37:141-156.

Pillars, R. B., D. L. Grooms, J. C. Gardiner, and J. B. Kaneene. 2011. Association between risk-assessment scores and individualcow Johne's disease-test status over time on seven Michigan, USA dairy herds. Prev. Vet. Med. 98:10-18.

Pithua, P., L. A. Espejo, S. M. Godden, and S. J. Wells. 2013. Is an individual calving pen better than a group calving pen for preventing transmission of Mycobacterium avium ssp. paratuberculosis in calves? Results from a field trial. Res. Vet. Sci. 95:398-404.

Raizman, E. A., J. Fetrow, S. J. Wells, S. M. Godden, M. J. Oakes, and G. Vazquez. 2007a. The association between Mycobacterium avium ssp. paratuberculosis faecal shedding or clinical Johne's disease and lactation performance on two Minnesota, USA dairy farms. Prev. Vet. Med. 78:179-195.

Raizman, E. A., S. J. Wells, S. M. Godden, J. Fetrow, and J. M. Oakes, 2007b. The association between culling due to clinical Johne's disease or the detection of Mycobacterium avium ssp. paratuberculosis faecal shedding and the diagnosis of clinical or subclinical diseases in two dairy herds in Minnesota, USA. Prev. Vet. Med. 80:166-178.

Rangel, S. J., J. Paré, E. Doré, J. C. Arango, G. Côté, S. Buczinski, O. Labrecque, J. H. Fairbrother, J. P. Roy, V. Wellemans, and G. Fecteau. 2015. A systematic review of risk factors associated with the introduction of Mycobacterium avium ssp. paratuberculosis (MAP) into dairy herds. Can. Vet. J. 56:169-177.

Ridge, S. E., C. Heuer, N. Cogger, A. Heck, S. Moor, I. M. Backer and S. Vaughan. 2010. Herd management practices and the transmission of Johne's disease within infected dairy herds in Victoria, Australia. Prev. Vet. Med. 95:186-197.

Smith, R. L., Y. T. Grohn, A. K. Pradhan, R. H. Whitlock, J. S. Van Kessel, J. M. Smith, D. R. Wolfgang, and Y. H. Schukken. 2009. A longitudinal study on the impact of Johne's disease status on milk production in individual cows. J. Dairy Sci. 92:2653-2661.

Smith, R. L., R. L. Strawderman, Y. H. Schukken, S. J. Wells, A. K. Pradhan, L. A. Espejo, R. H. Whitlock, J. S. Van Kessel, J. M. Smith, D. R. Wolfgang, and Y. T. Gröhn. 2010. Effect of Johne's disease status on reproduction and culling in dairy cattle. J. Dairy Sci. 93:3513-3524.

Sorge, U. S., K. Lissemore, A. Godkin, J. Jansen, S. Hendrick, S. Wells, and D. F. Kelton. 2012. Risk factors for herds to test positive for Mycobacterium avium ssp. paratuberculosis-antibodies with a commercial milk enzyme-linked immunosorbent assay (ELISA) in Ontario and western Canada. Can. Vet. J. 53:963-970.

Sweeney, R. W., M. T. Collins, A. P. Koets, S. M. McGuirk, and A. J. Roussel. 2012. Paratuberculosis (Johne's disease) in cattle and other susceptible species. J. Vet. Intern. Med. 26:1239-1250. 
Tiwari, A., J. A. VanLeeuwen, S. L. McKenna, G. P. Keffe, and H. W. Barkema. 2006. Johne's disease in Canada. Part I: Clinical symptoms, pathophysiology, diagnosis, and prevalence in dairy herds. Can. Vet. J. 47:874-882.

Vilar, A. L., C. S. Santos, C. L. Pimenta, T. D. Freitas, A. W. Brasil, I. J. Clementino, C. J. Alves, C. S. Bezerra, F. Riet-Correa, T. S. Oliveira, and S. S. Azevedo. 2015. Herd-level prevalence and associated risk factors for Mycobacterium avium ssp. paratuberculosis in cattle in the State of Paraíba, Northeastern Brazil. Prev. Vet. Med. 121:49-55. http://dx.doi.org/10.1016/j.prevetmed.2015.06.003.

Whittington, R. J., D. J. Marshall, P. J. Nicholls, I. B. Marsh, and L. A. Reddacliff. 2004. Survival and dormancy of Mycobacterium avium ssp. paratuberculosis in the environment. Appl. Environ. Microbiol. 70:2989-3004.

Whittington, R. J., and P. A. Windsor. 2009. In utero infection of cattle with Mycobacterium avium ssp. paratuberculosis: A critical review and meta-analysis. Vet. J. 179:60-69.
Windsor, P. A., and R. J. Whittington. 2010. Evidence for age susceptibility of cattle to Johne's disease. Vet. J. 184:37-44.

Wolf, R. 2014. Control of Mycobacterium avium subspecies paratuberculosis on Western Canadian dairy farms: Prevalence, diagnostics and risk factors. PhD Thesis. University of Calgary, Calgary, AB, Canada.

Wolf, R., F. Clement, H. W. Barkema, and K. Orsel. 2014. Economic evaluation of participation in a voluntary Johne's disease prevention and control program from a farmer's perspective- The Alberta Johne's Disease Initiative. J. Dairy Sci. 97:2822-2834.

Wolf, R., K. Orsel, J. De Buck, and H. W. Barkema. 2015. Calves shedding Mycobacterium avium subspecies paratuberculosis are common on infected dairy farms. Vet. Res. 46:71. 